\title{
GRUPOS FOCAIS NA INVESTIGAÇÃO QUALITATIVA DA IDENTIDADE ORGANIZACIONAL: EXEMPLO DE APLICAÇÃO*
}

\author{
FOCUS GROUPS IN THE QUALITATIVE INVESTIGATION \\ OF THE ORGANIZATIONAL IDENTITY: \\ EXAMPLE OF APPLICATION
}

\author{
Alexandra Flávio BUNCHAFT ${ }^{* *}$ \\ Sônia Maria Guedes GONDIM ${ }^{\star \star *}$
}

\begin{abstract}
RESUMO
Este artigo relata a experiência de aplicação dos grupos focais na investigação da identidade organizacional em uma cooperativa popular de trabalho. Foram realizados dois grupos focais com vinte costureiras da Cooperconfec, em Salvador. Fez-se uma análise de conteúdo das discussões grupais, na qual construíram-se representações gráficas dos significados de ser cooperada, das experiências de socialização profissional e das mudanças experimentadas com a inserção na cooperativa. Uma das conclusões é que a identidade organizacional constrói-se a partir da relação entre a cooperativa e a incubadora, da cooperativa com a comunidade, da relação interna entre as cooperadas e das cooperadas consigo mesmas.
\end{abstract}

Palavras-Chave : grupos focais, identidade organizacional, cooperativismo.

\begin{abstract}
This article discusses the application of focus groups in the investigation of the organizational identity of a work cooperative, Cooperconfec, located in
\end{abstract}

(*) Este artigo recebeu o apoio financeiro da CAPES à primeira autora através da concessão de uma bolsa de estudos para a realização de mestrado.

A bolsista de iniciação científica do PIBI/CNPq, 2003/2004, Girleide Feitosa, colaborou na transcrição das fitas de vídeo dos grupos focais realizados.

Este trabalho é derivado da coleta de dados que subsidiarão a dissertação de mestrado da primeira autora, da qual a segunda autora é sua orientadora.

(*) Psicóloga (UFBa), Especialista em Gênero e Desenvolvimento Regional (UFBa), Mestranda em Psicologia Social e do Trabalho (PPGPSI/CAPES/UFBa).

Endereço para Correspondência: R. Professor Lourival Pimenta Bastos, Lote 12 Quadra 34 - Costa Azul - Salvador/BA - CEP 41760-011 - E-mail: aleamado@hotmail.com

(*) Professora Doutora da Universidade Federal da Bahia (Departamento de Psicologia). Endereço para correspondência: Rua Rodrigo Argolo, 293, apt ${ }^{\circ}$ 502. Rio Vermelho Salvador - Bahia - CEP 41940-220 E-mail: sggondim@terra.com.br 


\begin{abstract}
Salvador. The attempt was to investigate the factors related to the organizational identity of a cooperative, since this is based on horizontal work relationships, as opposed to the labor market, characterized by verticality. Two focus groups were formed with twenty cooperades seamstresses. The procedure was to analyze thematic content of the results in order to support making graphical representations related to the meanings of being part of a cooperative, to the previous experiences of professional socialization, and to the changes experienced after being made part of the cooperative. One of the conclusions was that organizational identity is based on the connection of the cooperative to the incubator, on the impact of the cooperative in the community, on the group work experience, and on the change in personal image.
\end{abstract}

Key Words: focus groups, organizational identity, cooperativism.

Nos dias atuais é visível o aumento de publicações sobre grupos focais em revistas científicas, assim como da utilização desta técnica de pesquisa, tanto para servir a interesses teóricos em diversos campos do conhecimento (ciências sociais, educação, psicologia, etc.), quanto para viabilizar objetivos práticos de profissionais que usam os grupos focais como instrumento de gestão (Carlini-Cotrim, 1996; Morgan, 1987,1996; Gondim, 2002b). Na literatura brasileira, no entanto, ainda há um esparso número de artigos que discutem e explicitam, de modo mais detalhado, o emprego dessa técnica e os procedimentos de análise dos resultados.

O presente artigo tem o objetivo de apresentar um exemplo prático de aplicação, que evidencia como os grupos focais podem ser usados na investigação da identidade organizacional. A organização em estudo é a de uma cooperativa popular de trabalho, que está sendo objeto de pesquisa para fins de dissertação de mestrado da primeira autora deste artigo. Cabe destacar que a parceria técnico-financeira da Ong baiana Pangea - Centro de Estudos Socioambientais - com a Fundação Telefônica firmada desde janeiro de 2002 é que está viabilizando o processo de incubação ${ }^{1}$ da referida cooperativa.

O problema da pesquisa vem sendo demarcado a partir de três constatações relativas ao contexto de trabalho atual: i) as cooperativas de trabalho se apresentam como uma das alternativas produtivas para lidar com a crise gerada pelos altos níveis de desemprego, principalmente nas regiões mais pobres do país; ii) a construção da identidade organizacional em um empreendimento autogestionário, baseada em relações associativas de trabalho, se diferencia daquela baseada no modelo patrãoempregado; e iii) as experiências anteriores de socialização para o trabalho exercem um papel significativo na construção da identidade organizacional que, no caso específico dessa Cooperativa, se manifesta pelo fato de a atividade de costura ser considerada uma extensão das atividades femininas domésticas. (Bunchaft,2003)

A cooperativa em discussão é composta de vinte costureiras, em sua maior parte chefes de família, pertencentes à mesma classe social, e residentes no Subúrbio Ferroviário ${ }^{2}$ de Salvador, diferenciando-se apenas quanto à faixa etária, estado civil e experiência profissional prévia. As participantes possuem de 22 a 64 anos, sendo que dez possuem de 36 a 60 anos e nove encontram-se na faixa etária de 21 a 35 anos. Quanto ao estado civil, oito são solteiras, onze casadas e uma é viúva. Algumas das cooperadas são mulheres que nunca trabalharam fora de casa, outras tiveram experiências em atividades profissionais diversas e ainda outras possuem

(1) Termo utilizado para definir a experiência de capacitação e acompanhamento realizada por uma organização para cooperativas populares, às quais são oferecidas assistência técnico-financeira até que elas reúnam condições de auto-sustentabilidade. 
experiência anterior em costura, mas nenhuma delas participou previamente de um empreendimento autogestionário.

Em dois momentos distintos do funcionamento da cooperativa (avaliação feita por meio de questionário respondido por cada cooperada), observou-se que o significado do cooperativismo popular de trabalho, pela perspectiva das costureiras, foi expresso em cinco dimensões: social (foco na ajuda mútua), organizacional (foco no sentimento de pertencimento a um grupo organizado de trabalho), racional (foco na relação dos objetivos-fins- que orientam as ações-meios), político-econômica (foco na distribuição de poder e de ganhos) e legal (foco na institucionalização do grupo) (Bunchaft e Gondim, 2003).

O desafio ao longo do processo de incubação parece ser o de conciliar aspectos sociais, ideológicos e produtivos, visto que a adesão a valores coletivos é necessária, porém insuficiente para garantir a capacidade de autogestão, o que exige um duplo preparo dos cooperados: o de gestor social (co-partícipe do processo de gestão) e o de técnico-profissional (competência produtiva). Conforme a fase em que se encontra o processo de incubação, a ênfase da formação deverá recair no aspecto social (preparar o grupo para trabalhar de forma coletiva), técnico-gerencial (qualificar o grupo para o domínio técnico da atividade e da autogestão) ou ideológico (organizar e mobilizar o grupo para aderir aos princípios da economia solidária), sendo que estes três aspectos estão inter-relacionados e deverão oscilar, dependendo das necessidades da cooperativa e do perfil dos cooperados.

Observa-se, então, que acompanhar o processo de incubação torna-se relevante, na medida em que favorece a análise das chances de êxito de uma organização solidária, bem como permite a reorientação de ações para que os esforços na formação de cooperativas gerem resultados efetivos, ao procurar integrar os valores associativos ao processo produtivo (Bunchafte Gondim,2003).
Parte-se, portanto, da premissa de que há uma diferenciação na identidade organizacional de trabalhadores pertencentes a cooperativas populares de trabalho, que buscam manter relações laborais horizontais, em comparação àqueles que mantêm relações empregatícias verticais, baseadas no modelo hierárquico patrão-empregado. A partir desta premissa, procurou-se investigar os fatores significativos que estão associados à identidade organizacional de uma cooperativa popular de trabalho, em que foram utilizados os grupos focais como uma das técnicas de coleta de dados, já que se trata do estudo de um fenômeno grupal.

A primeira seção deste artigo situa os grupos focais na pesquisa qualitativa; a segunda relata a experiência de aplicação dos grupos focais na investigação da identidade organizacional da Cooperconfec e a terceira seção apresenta e discute a análise realizada a partir dos resultados obtidos na pesquisa. A quarta e última seção tece considerações finais sobre os desafios metodológicos e as futuras perspectivas do tema em questão.

\section{GRUPOS FOCAIS NA PESQUISA QUALITATIVA}

Há duas principais abordagens na produção do conhecimento científico nas ciências sociais: a nomotética ou quantitativa e a hermenêutica ou qualitativa. A quantitativa enfoca a relação entre a ciência social e a natural, valoriza a mensuração e o tratamento estatístico das variáveis como meios para a construção do conhecimento válido e generalizado. $\mathrm{Na}$ abordagem qualitativa, o enfoque, por sua vez, é na compreensão de um contexto particular, respaldando-se na interpretação, na busca de significado, na subjetividade e na intersubjetividade (Gondim,2002b, Kidd, 2002).

A interpretação do significado da experiência individual ou grupal é comumente obtida na pesquisa qualitativa pelo uso de técnicas, tais

(2) Região que possui, segundo o Censo 2000/IBGE, os mais elevados índices de pobreza e violência urbana da cidade de Salvador. 
como: entrevistas narrativas, episódicas, grupais, individuais, história de vida, grupos focais, observação participante, etnografia e pesquisa documental ${ }^{3}$. O foco deste artigo é nos grupos focais.

Dentre as distintas técnicas supracitadas, há autores que não fazem diferenciação entre grupos focais e entrevistas grupais, enquanto outros o fazem, baseando-se em dois aspectos: i) no foco da análise da pesquisa e ii) na relação que o pesquisador estabelece com os participantes, conforme ilustração do Quadro 1.

Para Gondim (2002b), o papel do entrevistador grupal é mais diretivo, estabelece uma relação dual com cada participante do grupo, de modo que ouve a opinião de cada um e as compara entre si. O nível de análise é individual. Ao contrário, o moderador de grupo focal não é diretivo, pois seu papel é o de facilitar o processo de conversação entre os membros de um grupo, deslocando seu interesse para a interinfluência de respostas que se produzem nas discussões grupais desencadeadas sobre um determinado assunto. As suas intervenções são pontuais, para esclarecer as opiniões emitidas, introduzir e concluir tópicos de discussão. O grupo é tomado como unidade de análise, ou seja, se uma posição é apresentada por um participante do grupo, mesmo não sendo partilhada por todos os outros integrantes, na análise dos resultados, é tomada como do grupo.

Existem, pelo menos, duas classificações de grupos focais, a de Morgan e a de Fern. Para
Morgan (1987; 1996), há três perspectivas no uso de grupos focais, que se diferenciam quanto à centralidade desta técnica para vir a responder ao problema da pesquisa. A primeira perspectiva é a do grupo focal auto-suficiente (self-contained), que considera a técnica como principal fonte de dados, por revelar aspectos oriundos dos processos de interação grupal, que não são facilmente acessíveis pela técnica de entrevista individual. Os dados obtidos são suficientes para dar resposta ao problema da pesquisa. A segunda perspectiva descreve o uso dos grupos focais como fonte preliminar de dados. Neste caso, os grupos focais atendem a finalidades exploratórias e servem para dar subsídios para a criação de itens de instrumentos (escalas, questionários, etc.) e para a realização de pré-testes. A terceira e última perspectiva é aquela que concebe a técnica como associada a outros métodos. Neste caso, os grupos focais são combinados a dois ou mais instrumentos de coleta de dados, com o objetivo da triangulação, ou seja, avaliar as possibilidades de se chegar a conclusões similares ou complementares partindo de um único objeto de estudo complexo.

A rigor, a técnica será usada de acordo com a perspectiva metodológica do pesquisador em relação ao objeto escolhido, com o nível de aprofundamento requerido e com o tipo de generalização a ser obtida, seja teórica ou empírica.

Para Fern (2001), há duas orientações quanto ao uso de grupos focais: a primeira é

Quadro 1.Distinção entre grupos focais e entrevistas grupais.

\begin{tabular}{lcl}
\hline \multicolumn{1}{c}{ Técnicas Qualitativas } & Foco de análise & Relação entre pesquisador e participantes \\
\hline Entrevista grupal & Individual & Relação dual com cada participante \\
Grupo Focal & Grupal & Relação com o grupo \\
\hline
\end{tabular}

(3) Para mais detalhes sobre estas técnicas, consultar as seguintes obras: Entrevista episódica de Uwe Flick (2002), Entrevista narrativa de Sandra Jovchelovitch \& Martin W. Bauer (2002), Entrevistas individuais e grupais de George Gaskell (2002), Entrevista episódica de Uwe Flick (2002), Entrevista narrativa de Sandra Jovchelovitch \& Martin W. Bauer (2002), Life History and the Postmodern Challenge de William G. Tierney (2000), Focus Group as Qualitative Research de David L. Morgan(2000), Participatory Action Research de Stephen Kemmis and Robin McTaggart (2000), Ethnography and Ethnographic Representation de Barbara Tedlock (2000) e The Interpretation of Documents and Material Culture de Ian Hodder (2000). 
teórica e tem como objetivo a produção de conhecimento científico e a segunda é prática, e se destina à utilização dos dados em contextos específicos para a intervenção e tomada de decisões. Ambas as orientações podem se combinar em três modalidades: a) grupos focais exploratórios, cujo enfoque é reunir informações significativas que permitam, não só a familiarização com o tema, mas também a construção de modelos teóricos; b) clínicos, cuja ênfase é no diagnóstico e intervenção terapêutica dos próprios participantes do grupo, muito usada na área de saúde em grupos de hipertensos, por exemplo; e c) vivenciais, cujo foco é no processo de aprendizagem grupal de uma equipe de trabalho, bastante usada na avaliação do impacto de programas do terceiro setor e na preparação de equipes multiprofissionais.

Com base nas classificações propostas por Morgan (1988;1996) e Fern (2001), os grupos focais neste caso foram considerados de duas formas: i) como técnica associada a outros métodos, visto que a identidade organizacional é um fenômeno grupal e complexo e, por estar em processo de construção na referida cooperativa (ainda incubada), deve ser abordado também por outras estratégias de coleta de dados, como a observação de campo e análise documental; ii) exploratórios com orientação teórica, isto é, centrados no desenvolvimento de concepções teóricas, pois se pretende identificar os fatores associados à identidade organizacional, possibilitando uma melhor compreensão de como ocorre a sua construção em empreendimentos autogestionários.

Em resumo, há três razões para utilizar os grupos focais na compreensão da identidade organizacional, a saber:i) o grupo de cooperadas já está constituído como um grupo de trabalho há aproximadamente dois anos, ii) a identidade organizacional é um fenômeno grupal e deve ser analisado por meio da interação grupal e iii) a cooperativa ainda se encontra em processo de incubação, o que repercute na construção da identidade organizacional, já que as pessoas estão formando suas opiniões e atitudes no interjogo das relações tanto do grupo de pares (cooperadas), quanto na relação com a organização responsável pela incubação (Pangea).

As duas próximas seções terão como objetivo detalhar os procedimentos adotados da técnica dos grupos focais na investigação sobre a identidade organizacional.

\section{A INVESTIGAÇÃO DA IDENTIDADE ORGANIZACIONAL POR MEIO DOS GRUPOS FOCAIS}

Nesta seção serão apresentados seis tópicos de discussão sobre a investigação da identidade organizacional por meio dos grupos focais, quais sejam: i) Aspectos conceituais da identidade organizacional, ii) Composição dos grupos focais, iii) Local de realização dos grupos focais, iv) Roteiro utilizado nos grupos, v) Forma de condução dos grupos focais e vi) Habilidades do moderador.

\subsection{Aspectos conceituais da identidade organizacional}

As concepcões clássicas de identidade organizacional surgiram a partir do trabalho pioneiro de Albert e Whetten (1985), autores que a definem como o conjunto de crenças partilhadas pelos seus membros sobre o que é central, distintivo e duradouro na organização. O critério de centralidade aponta a essência da organização. O de distintividade indica os elementos que diferenciam uma organização das outras com as quais poderia ser comparada. $\mathrm{O}$ de duração ressalta as características estáveis no tempo. Estes três critérios são utilizados para definir identidade organizacional.

Há autores que defendem a idéia da identidade organizacional como a forma pela qual a organização percebe a si mesma, estabelecendo ligações entre os estudos da identidade no campo organizacional e a psicologia social (Dutton, Duckerick e Harquail, 1994), enquanto outros discutem o conceito de identidade organizacional, considerando a forma como as 
organizações administram a sua imagem externa e como esta imagem as afeta (Blasick, 1988).

Caldas e Wood Jr. (1997) argumentam que o conceito de identidade, embora polêmico e complexo, é fundamental para a compreensão de fenômenos organizacionais, pelo fato de transitar por diferentes níveis e dimensões de análise, proporcionando novas perspectivas ao entendimento de questões não totalmente esclarecidas por abordagens como cultura, clima, comportamento e mudança organizacional. Estes autores trabalham o conceito de identidade vinculado aos fenômenos organizacionais e afirmam que, além do indivíduo, outras entidades podem ter identidade, sugerindo que tal conceito seja entendido a partir de duas dimensões: a do objeto focal (indivíduo, grupo e organização) e da observação (dos membros - interna - e dos não membros - externa).

Em resumo, a identidade é um fenômeno relacional, construído na oposição entre àquilo que há de comum e faz com que um indivíduo se perceba como membro de um grupo, compartilhando símbolos e significados, e aquilo que há de diferente e faz com que o indivíduo se perceba como não membro de um outro grupo. Sendo assim, definir uma identidade significa reconhecer as semelhanças internas ao grupo (endogrupo)e as diferenças com outros grupos (exogrupo) (Silva, 2000, Woodward, 2000).

Neste estudo, adotou-se a perspectiva de que a identidade organizacional se situa entre as características que unem as cooperadas em um grupo organizado de trabalho, respaldado em relações laborais horizontais, e o que as distinguem de outros grupos de costureiras, que se baseiam em relações verticais de trabalho.

\subsection{Composição dos grupos focais}

A preocupação em conhecer como se expressa a horizontalidade nas relações de trabalho e o reconhecimento de que o grupo de costureiras já existia há aproximadamente dois anos fizeram com que se optasse por dividi-las em dois subgrupos de 10 participantes para a realização dos grupos focais. Três critérios nortearam o planejamento dos grupos: i) assegurar a heterogeneidade das participantes nos dois subgrupos (idade, estado civil, experiência profissional prévia, etc.), ii) garantir um espaço físico que permitisse o registro adequado do processo de discussão (sala especial) e iii) preparar tecnicamente a moderadora para a condução efetiva dos grupos focais, visto que as costureiras estão sendo acompanhadas por ela desde a criação da referida cooperativa.

Cada grupo focal foi composto por 10 pessoas, número suficiente para todos terem a possibilidade de partilhar suas percepções, fornecer uma diversidade de opiniões e atingir a saturação das respostas de cada tópico proposto. A duração aproximada de cada uma das sessões foi de duas horas.

\subsection{Local de realização dos grupos focais}

Optou-se por alugar ${ }^{4}$ uma sala específica para a realização dos dois grupos focais que dispunha de um sistema de gravação em áudio e vídeo embutido, assim como de uma pequena sala de observação localizada atrás de um espelho unidirecional. A sala dispunha ainda de uma mesa retangular, com onze cadeiras distribuídas ao seu redor, frigobar, bandejas de salgados, cafés e água, armário contendo caneta pilot, papel ofício, revistas e o cavalete com folhas de flip chart.

\subsection{Roteiro utilizado nos grupos focais}

Para a condução dos grupos focais foi estruturado um roteiro de três questões para facilitar a dinâmica grupal, permitir um aprofundamento progressivo da discussão e fornecer insumos significativos para a análise dos fatores associados à identidade organizacional. As três questões norteadoras dos grupos (Quadro 2): i) O que é ser costureira da

(4) O custo médio do aluguel de um laboratório de grupo focal em Salvador é na faixa de 1 salário mínimo por grupo, sem contar com os honorários do moderador, caso haja necessidade de contratação. 
Cooperativa de Mulheres do Parque São Bartolomeu e no que se diferenciam de outros grupos de costureiras?; ii) Como foram preparadas para o trabalho e que tipo de experiências profissionais tiveram?; iii) Houve alguma mudança na sua vida, a partir do momento em que entraram na cooperativa? Se houve, quais foram?

\subsection{Forma de condução dos grupos focais}

Antes de iniciar a discussão em cada grupo, a moderadora dos grupos (primeira autora deste artigo) apresentou algumas regras de funcionamento: i) somente uma pessoa deve falar de cada vez; ii) conversas paralelas devem ser evitadas; iii) ninguém deve dominar a discussão; iv) todas têm o direito de falar o que pensam e v) o papel da moderadora é apenas introduzir novos temas ou perguntas e facilitar a discussão entre as participantes.

A sala especial em que foram realizados os dois grupos oferecia um sistema de comunicação interna entre a moderadora e a observadora ${ }^{5}$, por meio do ponto eletrônico, o que permitiu a comunicação entre ambas sem que houvesse a interrupção do fluxo de discussão. É oportuno alertar, no entanto, que o uso do ponto eletrônico apresenta vantagens e desvantagens. A vantagem é que um outro observador pode chamar a atenção para fatos ou eventos que estejam ocorrendo no grupo e fazer sugestões que ajudem na fluidez do processo de discussão. Um exemplo foi o que ocorreu no segundo subgrupo de cooperadas, que inicialmente se encontrava 'desaquecido' $\mathrm{e}$ foi, a partir desta comunicação, que se decidiu inverter a ordem das questões do roteiro, o que permitiu que a discussão seguisse seu curso. Por outro lado, a principal desvantagem no uso do ponto eletrônico é a ansiedade do observador, que pode se exceder no seu uso e vir a desconcentrar o moderador, fazendo com que perca pistas promissoras de exploração e aprofundamento da discussão $0^{6}$.

Alguns cuidados foram objeto de atenção na condução dos grupos focais: i) procurar deixar o grupo à vontade para expressar suas opiniões; ii) reafirmar, quando necessário, as regras de funcionamento dos grupos focais; iii) explorar ao máximo o tópico, antes que o grupo seguisse adiante na discussão; e iv) evitar digressões que distanciavam o grupo dos tópicos principais.

Quadro 2. Tópicos do roteiro e seus respectivos objetivos.

Questões do Roteiro

1) O que é ser costureira da Cooperativa de Mulheres do Parque São Bartolomeu e no que vocês se diferenciam de outras costureiras ?

2) Como vocês foram preparadas para o trabalho e que tipo de experiências anteriores tiveram?

3) Houve alguma mudança na vida de vocês, a partir do momento em que entraram na cooperativa? Se houve, Quais foram?

\section{Objetivos}

- Identificar o as características comuns ao grupo de trabalho e as diferenças em relação a outros grupos

- Inferir sobre os processos de socialização para o trabalho das cooperadas e se tais processos estariam associados, de algum modo, às formas como elas se percebem atualmente no trabalho.

- Identificar experiências comuns das costureiras a partir de sua inserção na cooperativa e seu impacto na vida pessoal, familiar e social.

\footnotetext{
(5) A observadora, neste caso, foi a segunda autora (orientadora de mestrado) que tem experiência com grupos focais desde 1998.

(6) É muito comum em pesquisas de mercado o moderador evitar o uso do ponto eletrônico, em decorrência do uso abusivo do recurso pelo cliente ou contratante, o que prejudica a concentração do moderador e dificulta a coordenação do processo de discussão.
} 
O fato de a moderadora dos grupos focais acompanhar o processo de implantação da cooperativa e, portanto, conhecer a trajetória dessa organização antes da realização dos grupos focais, facilitou a discussão entre os membros do grupo. Por esta mesma razão, foi necessário, no entanto, que a moderadora redobrasse sua atenção de modo a envolver todos os participantes no fluxo da discussão.

\subsection{Habilidades do moderador}

Não resta dúvida que, além de se preocupar com os registros dos grupos focais, roteiro, composição, local de realização, etc., é preciso preparar o moderador para exercer um papel que venha a facilitar o curso da discussão. Para tanto, se faz necessário um treinamento prévio do moderador para que, no momento da sessão, não ocorra, em vez do grupo focal, uma entrevista grupal. Em outras palavras, no grupo focal, a relação do moderador é com o grupo, seu papel é o de permitir que, ao sugerir o tema, os participantes do grupo compartilhem a sua opinião com os outros integrantes e não ao moderador. No caso da entrevista grupal, a relação é diádica, ou seja, o entrevistador quer saber o que cada participante pensa individualmente sobre o tema ou assunto.

Uma responsabilidade adicional do moderador no uso da técnica é a preocupação ética de zelar pela preservação da privacidade dos membros dos grupos, evitando que os participantes exponham demais seus sentimentos (o que seria pertinente em um grupo focal clínico, mas contra-indicado para um de pesquisa). Em se tratando dos grupos focais aqui descritos, o cuidado foi de assegurar que a expressão de sentimentos pessoais ou comuns a todo grupo não provocasse constrangimentos a qualquer uma das participantes. No segundo grupo focal, por exemplo, uma cooperada fez críticas à forma de distribuição do trabalho na cooperativa, sugerindo que o trabalho era concedido sempre às mesmas pessoas. Várias outras cooperadas rapidamente contra-argumentaram, dizendo que ela não participava regularmente das atividades da cooperativa, deixando muito evidente a sua insatisfação com a conduta da referida cooperada. O Quadro 3 resume as principais habilidades requeridas de um moderador de grupo focal.

Quadro 3. Principais habilidades de um moderador de grupo focal

- EMPATIA

- ATENÇÃo FlutuANTRE

- DOMÍNIO DO TEMA

- AUtOCONTROlE

- AUTODOMíNIO

- PRESTEZA NOS FEEDBACKS

A empatia é fundamental para que o moderador se coloque no lugar do participante $e$ compreenda o seu ponto de vista. A atenção flutuante irá favorecer as intervenções pontuais no processo de discussão, permitindo trazer para o centro dos comentários pontos de vista discordantes, quando ignorados pela maioria do grupo. O domínio do tema é essencial para permitir um acompanhamento cuidadoso das trocas verbais. O autocontrole e o autodomínio são importantes para que o moderador iniba sinais de sua concordância ou discordância em relação aos pontos de vista tratados no grupo. Por último, a presteza nos feedbacks é um requisito valioso para que o moderador avalie 0 sentido de suas interpretações acerca do discurso dos participantes.

Nesta seção foi apresentado o conceito de identidade organizacional, bem como foram explicitados os procedimentos de realização dos dois grupos focais com as costureiras da Cooperativa do Parque São Bartolomeu. A seguir, a análise dos resultados será objeto de atenção.

\section{ANÁLISE DOS RESULTADOS}

A técnica dos grupos focais permite apreender o fenômeno investigado no nível 
transversal, ou seja, são apreendidos os aspectos contingenciais que emergem a partir do momento que ogrupo se reúne em um determinado momento e lugar.

A escassez de modelos de análise de grupo em psicologia torna os procedimentos de análise de resultados um esforço ainda bastante solitário do pesquisador. É inegável a existência de inúmeros recursos técnicos que viabilizam a análise de textos escritos e de falas, tais como a análise de conteúdo, a análise de discurso e a análise argumentativa, mas ainda há muito pouco consenso sobre tomar o grupo como uma unidade de análise (Gondim, 2002b). No entendimento das autoras deste artigo, considerar o grupo como unidade de análise significa identificar posições diversificadas em relação a um tópico específico e que são desencadeadas no processo de interação grupal.

A análise da identidade organizacional das cooperadas foi orientada pelas três questões que nortearam a discussão nos dois grupos: o que é ser cooperada (o que as une e diferencia dos outros grupos), os processos de socialização para o trabalho que antecederam o ingresso na cooperativa e as mudanças na vida pessoal, familiar e social após a inserção na cooperativa.

A partir da transcrição das fitas de vídeo e áudio, foi feita uma análise de conteúdo temática, não quantitativa (Bardin,1970, Smith, 2000). As transcrições foram realizadas separadamente por dois avaliadores: pela moderadora e por uma bolsista de iniciação científica que não havia participado de nenhum dos dois grupos focais como observadora. A partir das transcrições, procurou-se sublinhar os temas centrais de cada grupo, tomando como base os tópicos do roteiro que nortearam a discussão. Construíram-se representações gráficas dos temas e argumentos centrais, muito semelhante à perspectiva dos mapas cognitivos ${ }^{7}$.

Em ambos os grupos, as cooperadas trouxeram à discussão a sua diferença em relação aos outros grupos de trabalho: serem donas de seu próprio negócio, o que lhes dá uma profissão e uma valorização social (Mapa 1). A propriedade do negócio parece estar associada à ausência de chefia, de horários prefixados e de carteira assinada.

Para as cooperadas, ser costureira da cooperativa envolve quatro tipos de relação: i) com a incubadora, 2) com a comunidade, 3) entre as cooperadas e 4) consigo mesma. Do ponto de vista da relação entre a cooperativa e a incubadora, o apoio técnico-financeiro recebido, o incentivo ao aprimoramento da costura e a diversificação da sua qualificação técnica (estilismo, modelagem), a partir de parcerias com entidades públicas, as qualificam e as diferenciam de outros grupos de costureiras. As cooperadas, no entanto, não ignoram que o vínculo com a incubadora é provisório e a preocupação com a auto-sustentabilidade emerge, o que parece ter justificado a discussão da necessidade de serem mais preparadas para a autogestão, por meio de uma maior participação nos processos decisórios da cooperativa e no gerenciamento da loja que adquiriram em um shopping da cidade. “(...) E a cooperativa nossa tem muitas coisas que outras não têm, é apoio(...) porque sozinha é mais difícil e os apoios que a gente tem encontrado tá favorecendo que a gente venha a subir, então prá chegar lá no topo depende de nós".

Na relação entre a cooperativa e a comunidade, discutiu-se a presença da cooperativa na mídia e de que modo estaria repercutindo na projeção tanto da comunidade quanto do próprio grupo, porém algumas ressaltaram que, além do orgulho que sentem, há também o receio de não conseguir manter essa imagem bem sucedida depois de concluída a incubação.

Quanto às relações internas entre as próprias cooperadas, conseguiu-se identificar cinco aspectos principais: i) as críticas à cooperativa provêm das integrantes que estão ausentes de seu cotidiano e que não incorporaram os valores do cooperativismo, ii) a existência de conflitos internos é devido à heterogeneidade

\footnotetext{
(7) Os mapas cognitivos são empregados para compreender situações organizacionais, buscando identificar padrões de percepções no nível de análise grupal, individual ou organizacional (Bastos,2000).
} 
Mapa 1: O que é ser costureira de uma cooperativa e o que a diferencia de outros grupos?

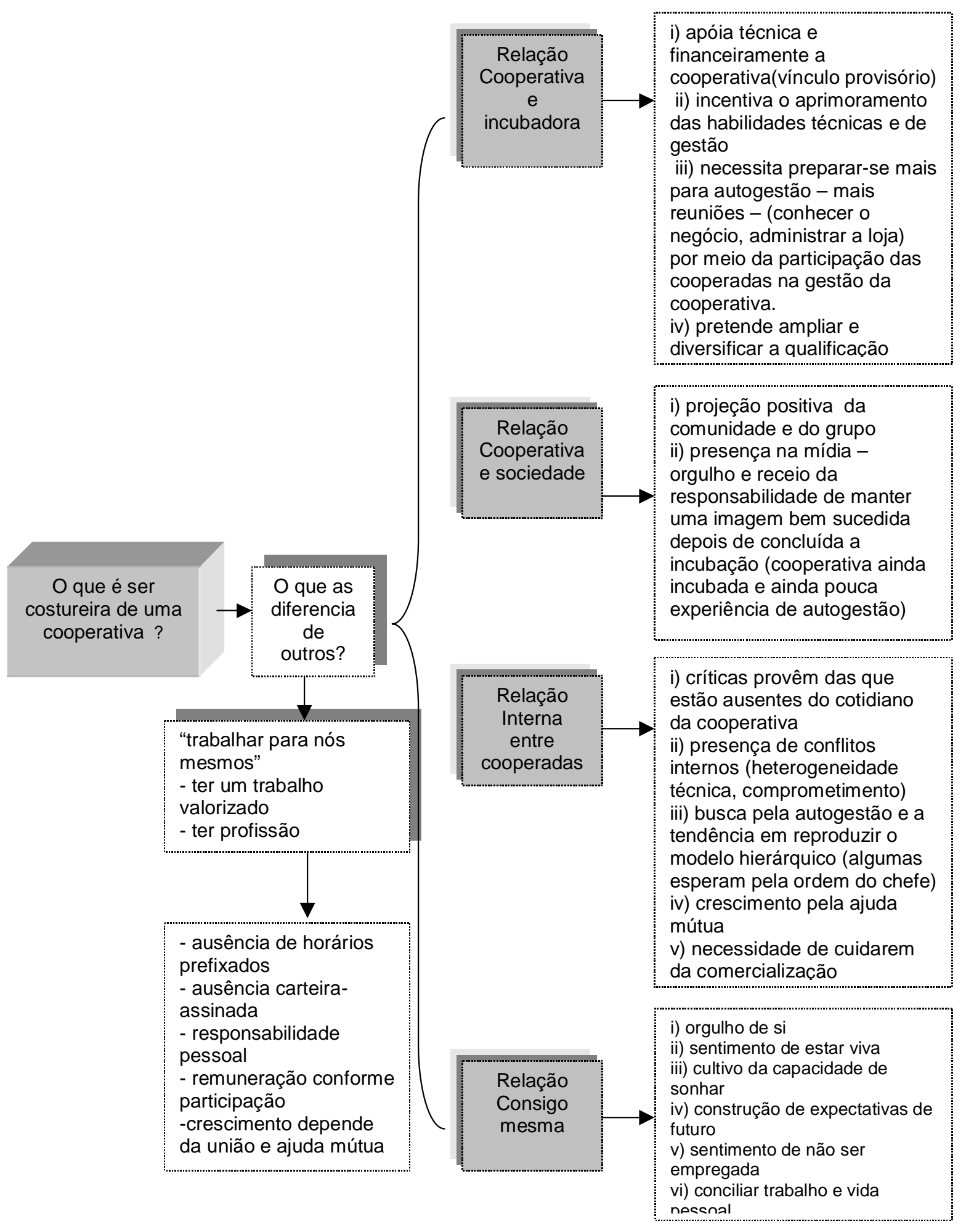


técnica do grupo e aos níveis diferenciados de comprometimento organizacional, iii) ao mesmo tempo em que há uma busca da autogestão, há uma tendência em reproduzir o modelo hierárquico de relações de trabalho em que algumas esperam pela ordem do chefe, iv) o crescimento da cooperativa só virá com a ajuda mútua e o pensamento coletivo não imediatista, para que os produtos tenham qualidade e possam conquistar credibilidade no mercado e v) é preciso preparar um grupo para atuar na comercialização e garantir a manutenção da organização no mercado.

Do ponto de vista pessoal, as cooperadas destacam que ser costureira da cooperativa faz com que se sintam orgulhosas por terem conquistado uma identidade profissional e experimentarem o sentimento de estar em vivas. Além disto, destacam o quanto é importante não estarem na condição de empregadas, e poderem conciliar trabalho e vida pessoal. "Bom, eu acho excelente né, porque a gente não se sente empregada(...) temos tempo para nós e para nosso serviço".

O segundo foco de análise foi relativo aos processos de socialização para o trabalho. Os resultados das discussões se encontram categorizados no Mapa 2. Algumas cooperadas contaram que foram preparadas para a atividade de costura durante as fases da infância e adolescência, em decorrência do modelo materno (mãe costureira) e das brincadeiras infantis, nas quais costuravam roupas de bonecas. A familiaridade com a costura na infância pode ter contribuído para que algumas delas viessem a exercer estas atividade no âmbito doméstico, costurando roupas para si e para a família ou para terceiros. Houve relatos também de costureiras que trabalharam em fábrica e, segundo elas, a diferença deste vínculo empregatício em relação à experiência da cooperativa está nas formas de

Mapa 2. Processos de socialização para o trabalho

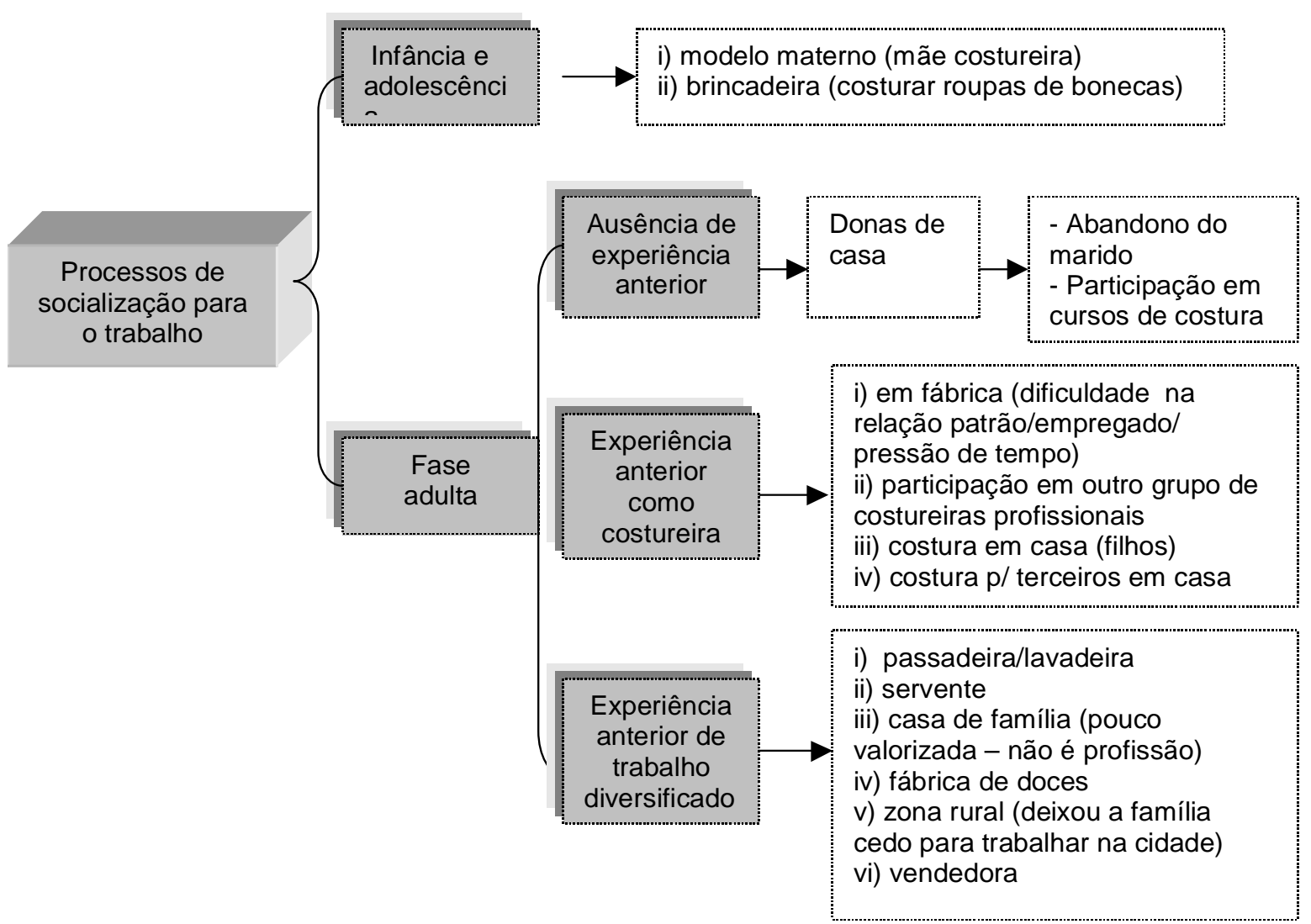


gestão destes empreendimentos. Outras, no entanto, disseram não estarem familiarizadas com a atividade de costura e tiveram experiências diversificadas de trabalho (passadeira, servente, lavadeira, vendedora, trabalhadora rural, etc.). Algumas cooperadas relataram também ter trabalhado em "casas de família", mas percebem este trabalho como não sendo valorizado pela sociedade. Um outro aspecto significativo da discussão foi que algumas mulheres nunca exerceram atividade profissional remunerada antes de ingressar na cooperativa. "(...) eu nunca trabalhei, eu sempre vivi pros outros, então agora é o momento de eu poder fazer alguma coisa pra mim, dizer eu trabalho".

A inserção na cooperativa parece ter gerado quatro níveis de impacto na vida das cooperadas (Mapa 3): no seu papel na comunidade, na

Mapa 3. Mudanças a partir da inserção na cooperativa de trabalho

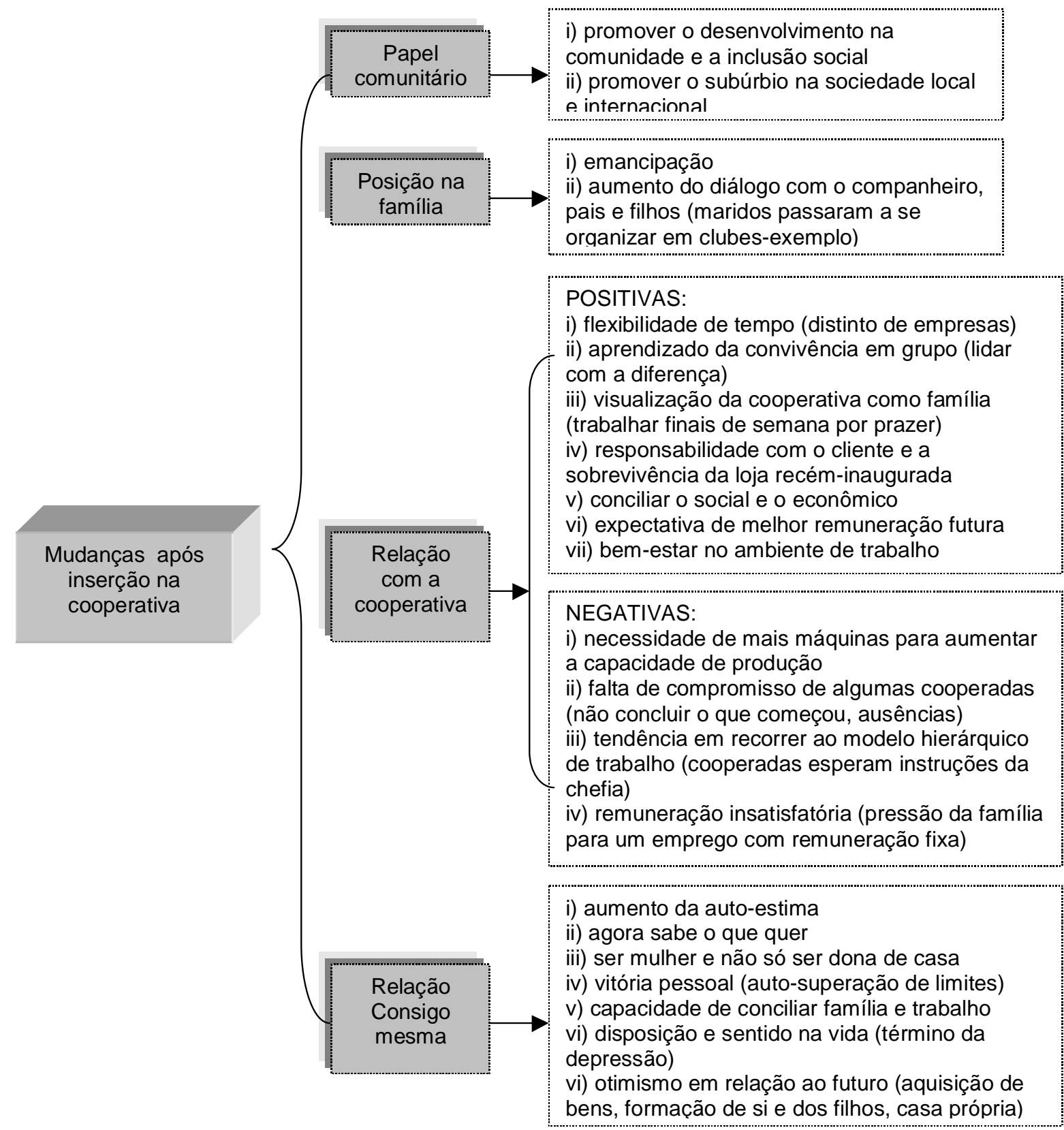


família, na vida pessoal e na relação com a cooperativa.

As cooperadas argumentam que a cooperativa está projetando a imagem do Subúrbio, promovendo o desenvolvimento local e a inclusão social de pessoas da região, o que será mais intensificado a partir da aquisição de um espaço físico maior e com mais máquinas, aumentando a capacidade produtiva da organização. "(...)A experiência é boa não só no bairro como lá fora, sair no jornal ?(...) a não ser que acontecesse uma tragédia, agora não, tem um grupo representando o bairro lá fora, a cooperativa".

No plano familiar, os dados demonstram que a cooperativa favoreceu a emancipação das cooperadas, tendo contribuído também para a ampliação do diálogo com os filhos, pais e companheiros. De um lado, a cooperativa as tem ajudado a ter bem-estar no ambiente profissional e administrar melhor o tempo para o trabalho e a família. No âmbito do grupo, a convivência as capacita a lidar com a diferença (aspecto social) e com responsabilidades cada vez maiores relativas ao cliente, pois reconhecem que a remuneração está vinculada ao sucesso da cooperativa (aspecto econômico). De outro lado, refletem sobre os aspectos negativos a serem vencidos. Para aumentar a capacidade produtiva é necessário ter mais máquinas e maior comprometimento organizacional. Apesar da cuidadosa preparação das cooperadas para trabalharem com a autogestão, algumas adotam uma postura próxima do modelo hierárquico de trabalho, esperando instruções da chefia. A insatisfação com a remuneração atual, bastante comum no início de empreendimentos desse tipo, é agravada pela pressão da família por uma remuneração fixa, o que faz com que algumas mantenham atividades externas remuneradas.

Por último, é digno de nota o impacto da cooperativa na vida pessoal. Uma identidade profissional parece ter sido conquistada -"agora sei o que quero"-, há aumento da auto-estima e do sentimento de ser mulher e não somente dona de casa. O sentido da vida sofre mudança devido ao exercício de auto-superação de limites, atitudes de otimismo em relação ao futuro e fim da depressão. "(...) quando eu tava em casa, fazia as coisas, dormia, assistia televisão e sentia depressão, chorava muito (...), não tinha nada, não tinha futuro (...) aí quando fui pra cooperativa e comecei a ter convivência com aquele pessoal todo, tomar aquelas aulas e depois fui pra costura, aí eu chego em casa cansada, mas tô satisfeitíssima" .

\section{CONSIDERAÇÕES FINAIS}

O objetivo deste artigo foi dar diretrizes gerais e um exemplo mais detalhado de como é possível investigar a identidade organizacional, para que possa servir de referência na investigação cognitiva de fenômenos grupais.

A identidade organizacional, por ser um fenômeno grupal, foi investigada a partir do uso da técnica de grupos focais, que toma o grupo como unidade de análise. Parte-se da premissa de que a formação de opiniões sobre si mesmo e as coisas do mundo se dá no contexto de interação social. Neste sentido, a identidade organizacional foi considerada resultante dos significados compartilhados pelos membros da organização, a partir das interações sociais estabelecidas durante os grupos de discussão.

Observou-se que a identidade organizacional, neste caso, está em processo de construção, não se configurando como uma entidade autônoma, estática e duradoura, já que a Cooperconfec se encontra em incubação, ou seja, sendo acompanhada por uma outra organização, que oferece assistência técnicofinanceira até que ela reúna condições de autosustentabilidade.

Infere-se que a organização, pela perspectiva das cooperadas, pode ser compreendida a partir de quatro níveis de relação: 1)entre a cooperativa e a incubadora, 2) entre a cooperativa e a comunidade, 3) entre as cooperadas e 4) consigo mesma, conforme quadro 4. 


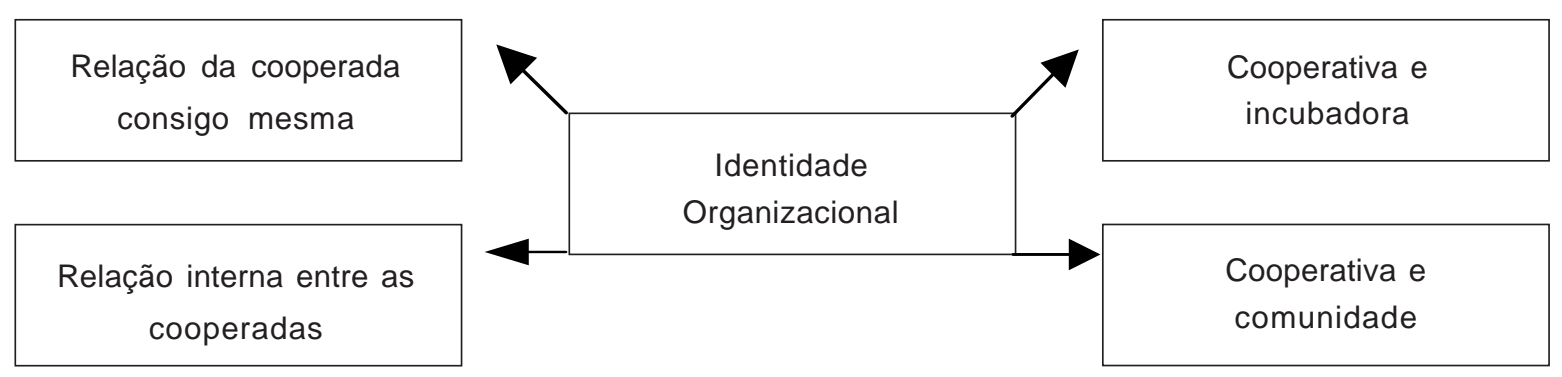

Não se pode desconsiderar que a técnica dos grupos focais faz um recorte transversal do objeto de estudo, o que quer dizer que a análise aqui apresentada é circunscrita às interações sociais ocorridas durante a realização dos grupos em um momento dado. É inegável que como o processo é dinâmico, algumas mudanças podem já ter ocorrido nessa identidade organizacional. O discurso de ser dono do próprio negócio, assim como a importância da ajuda mútua, parece estar fortemente incorporado pelas cooperadas. Este entendimento é conseguido pela forte convicção de que a cooperativa trouxe ganhos pessoais e sociais para cada uma delas e para a comunidade na qual estão inseridas, assim como trouxe apreensão. Veio à tona, na discussão, o receio de não conseguir sobreviver no mercado sem o apoio da organização incubadora.

No que tange à administração, a cooperativa parece encontrar-se em um espaço híbrido de gestão, oscilando entre a heterogestão (papel mais ativo da incubadora na orientação dos processos da cooperativa) e a busca pela autogestão, ou seja, ora a organização funciona baseando-se no modelo hierárquico da relação patrão-empregado, na qual as ordens e instruções fluem de cima para baixo, ora se encontra buscando o exercício da autogestão no qual as lideranças têm a função de organizar o trabalho e não de dar ordens.

Quanto à técnica utilizada nesta pesquisa, vale ressaltar que os grupos focais podem ser utilizados em conjunto com outros métodos de investigação, notadamente quando se investiga um fenômeno grupal complexo, que precisa ser avaliado por meio de outros olhares, tais como observação participante, entrevistas e análise documental. Alguns autores expõem vantagens e limites no uso de grupos focais. A agilidade da coleta de dados, a apreensão de um fenômeno que emerge das interações grupais, a relação direta com os participantes e a amplitude de diversificação de respostas ilustram algumas de suas principais vantagens. Em contrapartida, a impossibilidade de fazer generalizações empíricas de seus resultados, a subjetividade do moderador e a abordagem apenas no nível verbal são alguns de seus limites.

Acredita-se que exista ainda um longo caminho a ser percorrido para que o uso da técnica de grupos focais atinja um bom nível de amadurecimento teórico e metodológico, em especial no que diz respeito ao aprimoramento da análise de seus resultados. Esta dificuldade é compartilhada por aqueles que estão familiarizados com pesquisas qualitativas, em que se depara com um volume expressivo de material para ser codificado e categorizado.

\section{REFERÊNCIAS BIBLIOGRÁFICAS}

ALBERT, S. \& WHETTEN, D. A. Organizational identity In : CUMMINGS, L.L. \& STAW, B. M.(Eds), Research in Organizational Behaviour, v. 7, pp. 263-295, Greenwich, CT: JAI Press, 1985.

BARDIN, L. Análise de conteúdo. Lisboa, Edições 70,1977.

BASTOS, A .V. B. Organização e cognição: o que emerge desta interface? In: RODRIGUES, S. B., PINA, M.(orgs.). Estudos Organizacionais: Novas perspectivas na administração de empresas. São Paulo : Iglu, 2000. 
BLASICK, J. The communication of organizational identity : a source of competitive advantage. Paper apresentado durante as reuniões anuais da Academy of Management, Cincinnati, $\mathrm{OH}$, 1988.

BUNCHAFT, A. F. A construção da identidade profissional em uma cooperativa popular de trabalho: A Cooperativa de Mulheres do Parque São Bartolomeu, Projeto de Dissertação de Mestrado apresentado no I Seminário de Qualificação do Programa de Pós-Graduação em Psicologia/PPGPSI, UFBA, abril, 2003.

BUNCHAFT, A. F. \& GONDIM, S. M.G. O significado do cooperativismo popular de trabalho: O caso da Cooperativa de Mulheres do Parque São Bartolomeu, prelo, 2003.

CALDAS, M. P. \& WOOD JR., T. Identidade Organizacional, In: Organização, Recursos Humanos e Planejamento, Revista de Administração de Empresas/EAESP/FGV, São Paulo, v.37, n.1, p.-06-17,1997.

CARLINI-COTRIM, B. Potencialidades da técnica qualitativa do grupo focal em investigações sobre abuso de substâncias. Revista de Saúde Pública. 30(3), 285-93, 1996.

DUTTON, J. E., DUKERICH, J. M. HARQUAIL, C. V. Op. cit. : ELSBACH, K.D. \& KRAMER, R. M. Cognitive strategies for managing organizational identity : a study of business school responses to the Business Week rankings. Paper apresentado durante as reuniões anuais da Academy of Management, Dallas, TX, 1994.
FERN, E. F. Advanced focus group research. California: Thousand Oaks, 2001.

GONDIM,S.M.G. Grupos Focais como Técnica de Investigação Qualitativa :Desafios Metodológicos. Revista Paidéia. Cadernos de Psicologia e Educação. v.12, n.24, pp.149-161, 2002b.

KIDD, S. A. The Role of Qualitative Research in Psychological Journals. Psychological Methods. v 7(1), pp.126-138, 2002.

MORGAN, David L. Focus group as a qualitative research. Qualitative Research Methods Series. 16. London: Sage Publications, 1987. Focus groups. Annual Review of Sociology. 22, pp.129-152,1996.

SILVA, T. T. A produção social da identidade e da diferença. In: (org.) Identidade e diferença: A perspectiva dos estudos culturais. Petrópolis, Vozes, pp.7-72, 2000.

SMITH, C. P. Content Analysis and narrative analysis. In : H.T. Reis \& C . M. Judd (Orgs). Handbook of Research Methods in social and personality psychology, pp. 313-335. Cambridge : Cambridge University Press, 2000.

WOODWARD, K. Identidade e diferença: Uma introdução teórica e conceitual. In: Silva, T. T. (org.) Identidade e diferença: A perspectiva dos estudos culturais. Petrópolis, Vozes, pp.7-72, 2000.

Recebido para publicação em 10 de outubro de 2003 e aceito em 15 de março de 2004. 
